\title{
Latex fluids are endowed with insect repellent activity not specifically related to their proteins or volatile substances
}

\author{
Márcio V. Ramos ${ }^{1 *}$, Eliane S. Araújo ${ }^{1}$, Raquel S. B. Oliveira1', Fabiano M. Teixeira ${ }^{1}$, \\ Danielle A. Pereira', Mariana G. Cavalheiro' ${ }^{1}$, Diego P. Souza', Jefferson S. Oliveira', \\ Cleverson D. T. de Freitas ${ }^{2 *}$.
}

\footnotetext{
${ }^{1}$ Departamento de Bioquímica e Biologia Molecular, Universidade Federal do Ceará, Campus do Pici, Bloco 907. Fortaleza-Ceará, Brasil. CEP. 60.451-970.

${ }^{2}$ Departamento de Biologia, Universidade Federal do Piauí, Campus Floriano, BR 343, Km 3,5, Bairro Melladão, Brasil.CEP 64800-000.
}
*Corresponding authors: Márcio V. Ramos (vramos@ufc.br) and Cleverson DT Freitas (cleversondiniz@hotmail. com) (FAX/Phone: +55 853366 9789)
Received: 27 September 2010; Accepted: 20 March 2011.

\begin{abstract}
Latex is an endogenous milky fluid synthesized and accumulated under pressure in a network of laticifer cells. In this study, latices from five plant species were examined for deterrent effect on oviposition of two Coleoptera (Bruchidae) pests. The latex from Euphorbia tirucalli, Calotropis procera and Plumeria rubrae exhibited deterrent activity on oviposition of both Callosobruchus maculatusand Zabrotis subfasciatus beetles. The latex from Cryptostegia grandiflora and Himathantus drasticus were less effective to $C$. maculatus and $Z$. subfasciatus oviposition, respectively. Eggs laid on latex-treated seeds were not affected.The emergence and the mean time of development and weight of larvae grown in treated seeds were similar to the controls. The deterrent activity of $C$. procera and $P$. rubra was dose and time-dependent for $Z$. subfasciatus rather than to $C$. maculatus. The deterrent effect was completely eliminated if the whole latices were fractionated in protein fractions, rubber and small metabolites. Exposing insects to crude latices did not alter ovipostion on untreated seeds. These results suggest that latices possess deterrent activity on insect oviposition mediated by a repellent effect, but that proteins and volatile substances are probably not involved. The repellent-like activity can be considered as a defensive role played by these fluids that relies on the combined action of their components.
\end{abstract}

Key words: Calotropis procera; deterrent activity; insect; laticifers; proteins; Plumeria rubra.

\section{INTRODUCTION}

In the course of evolution, plants have developed diverse morphological, functional and chemical adaptations to face the broad range of natural enemies. In fact, vascular plants, the most evolved plant group, need to protect themselves against the potential attack by highly diverse organisms including phytopatogens such as fungi, bacteria and virus, and also herbivores like beetles and caterpillars, concomitantly. Such necessities have certainly contributed positively to the appearance of specialized and integrated defensive mechanisms in plants (Kekwick, 2001; Papachristou et al., 2003; Pickard et al., 2008). More than 12.000 vascular plants possess a tubelike cell system which is frequently distributed throughout the body of the plant. The differentiated and specialized cells forming this network are thin, elongated and can growth intrusively (Hagel et al., 2008). Alternatively, 
the differentiated cells organize themselves in a row disposition and no rarely communicate one to each other. These particular structures have been defined as laticifers (Kekwick, 2001). Laticifer cells perform intense metabolic activity and in addition to the presence of typical Eukaryotic sub-cellular structures they synthesize and accumulate, under pressure, numerous distinct metabolites (Selvaraj et al., 1984; Han et al., 2000; Kalita and Saikia, 2004; Freitas et al., 2007; Farias et al., 2007). Studies performed aiming at understanding the biochemical profile of latex have offered convincing evidence for a defensive role played by these saps(Azarkan et al., 1997; Freitas et al., 2007; Ramos et al., 2009). Latices have been implicated in acute and chronic harmful effects on mammals (AlMezaine et al., 2005; Turillazzi et al., 2008; Albuquerque et al., 2009). Detrimental and toxic effects of laticifer proteins from the latex of Calotropis procera have been reported on important crop pests (Ramos et al., 2007, 2010). Different latex proteins seem to participate in defensive approaches against insects (Konno et al., 2004). Furthermore, latex has been shown to repel insects (Singhi et al., 2004). In this study, laticifer fluids collected from five distinct plants were evaluated for repellent activity by analyzing the deterrent activity on oviposition of two distinct Bruchidae pests.

\section{MATERIALS AND METHODS}

Plant material: Healthy and non-cultivated plants growing in the vicinity of Fortaleza-Brazil, were used as the source of fresh latex. The plant materials were identified by a taxonomist and the vouchers N.32663 (C. procera), N. 040409 (Cr. grandiflora),N. 040408 (H. drasticus) Apocynaceae; N. 15018 (P. rubra) - Asclepiadaceae and N. 38702 (E. tirucalli) - Euphorbiaceae were deposited at the Prisco Bezerra Herbarium of the Universidade Federal do Ceara, Brazil.

Latex processing: The latex of Calotropis procera and Plumeria rubra were collected by cutting the petiole of the youngest leaves and left to flow off in distilled water to obtain a 1:1 (v:v) ratio. The latex Cryptostegia grandiflora and Euphorbia tirucalii were collected by cutting ends of branches. The latex of Himathantus drasticus was collected from the stem following the same procedure for $C$. procera and $P$. rubra. The mixtures were gently agitated during collection to overcome the tendency of the coagulation-like effect of the materials. After being collected latices were immediately used in the experiments or processed in the laboratory to obtain the soluble protein fractions, rubber fractions and water of dialysis.

Laticifer fractions: To obtain the protein fraction of the laticifer fluids, the latex samples were centrifuged at $4^{\circ} \mathrm{C}$ for $10 \mathrm{~min}$ and $5,000 \mathrm{~g}$. The rubber-like precipitates arisen after centrifugation were separated and the supernatants were dialyzed in distilled water using membranes of 8,000 molecular mass cut-off. The dialyses water was renewed three times daily and the samples were maintained at $8^{\circ} \mathrm{C}$ for $60 \mathrm{~h}$. The materials retained by the membrane were newly centrifuged using the same conditions described above. The soluble, rubber-free supernatants were freeze dried and stored at $25^{\circ} \mathrm{C}$ until use. This protocol yielded almost all soluble proteins from the latices. The rubber fraction was obtained after the first step of centrifugation of the whole latices. The precipitated material, named rubber fraction, after separated, was washed three times with distilled water and suspended in distilled water to be assayed in repellent assays. The fraction named water of dialysis was prepared after removing the rubber fraction. After the first step of centrifugation of the whole latices, the supernatants had their total volume measured and were submitted to dialysis in distilled water for one hour in an identical volume. The water of dialysis was recovered and used in repellent assays. The water of dialysis was expected to join small water soluble molecules, including short peptides that migrated from the dialysis tube to the water surround it.

Insects: Cultures of Callosobruchus maculatus and Zabrotis subfasciatus were maintained separately on commercial seeds of cowpea [Vigna unguiculataL. (Walp)]. Insects were reared in a growth chamber at $27 \pm 2^{\circ} \mathrm{C}, 60-70 \%$ relative humidity and with a light/dark photoperiod of 12:12 $\mathrm{h}$. For the bioassays, two day-old adults were used. These pests were chosen because both attack seeds exclusively and laticifers are usually absent in seeds. 
Bioassays: The same batch of seeds of $V$. unguiculata was used in all bioassays. The seeds were handled with gloves. At least forty seeds were used for each analysis. Controls were made of four replicates of ten seeds each. Bioassay N. 1 was performed to determine the effect of latices on oviposition. With aid of pincers, seeds of Vigna unguiculata were individually immersed in the appropriate latex solution for $30 \mathrm{sec}$ and left to dry for 15 min on a non-absorbent surface under a controlled low wind flow. The seeds were then divided into 4 groups $(n=40)$ and deposited in transparent plastic pots perforated to permit air changes. Following the same protocol already described, seeds were first treated with a $1 \%$ gelatin solution $\left(\sim 35^{\circ} \mathrm{C}\right)$ and after being left to dry they were further treated with appropriate latex solution. In the last experimental group, seeds were treated solely with the gelatin solution (1\%). Gelatin was used because it has a clinging effect which may help the fixation of latex compounds in the coat of seeds.

Bioassay N2 was performed to investigate the possible involvement of latex proteins, rubber or small metabolites on the deterrent activity. For this, seeds of $V$. unguiculata were coated with laticifer protein fractions (1\%) prepared in distilled water, water of dialysis or rubber fraction, according to the same protocol cited before. Gelatin-coated seeds were used as control.

For both bioassays, after coating and dividing the seeds in the pots, five couples of insects were introduced in the replicates and left in the growth chamber for $24 \mathrm{~h}$ under the same conditions as the colonies source of insects. After an additional $24 \mathrm{~h}$, the insects were discarded and the number of eggs laid on the seeds was recorded to estimate the deterrent activity. The number of eggs was then adjusted to five per seed and the seeds were stored again in the growth chamber until day 17 after ovipostion. At the end of the experiment, the seeds were opened and the number of larvae and larval weight were recorded.

Bioassay N. 3 was designed to evaluate the deterrent activity during different periods of time. The laticifer fluids of $C$. procera and $P$. rubra were used. For this, a set of seeds was coated separately with the fluids and stored in the growth chamber. At intervals of time corresponding to zero,
$6,12,24,48,72,360$ (15 days) and $720 \mathrm{~h}$ (30 days), five couples of insects were introduced in the pots corresponding to four replicates of ten seeds to allow oviposition for $24 \mathrm{~h}$. The number of eggs laid along this time was recorded and compared to the control formed of crude seeds.

Two distinct assays were performed to investigate whether any deterrent effect was caused by repellence provoked by volatile compounds found in the fluids. For the bioassay N. 4, latex was collected and maintained overnight under sterile conditions, stirring and circulating air to stimulate evaporation of volatile compounds. The initial volume was measured and $24 \mathrm{~h}$ later was adjusted with distilled water in order to recover the initial volume. This sample was used to coat the seeds as described before and deterrent activity was evaluated. For the bioassay N. 5 , five couples of insects and small recipients containing $3 \mathrm{~mL}$ of fresh crude latices (collected without water) were joined in closed recipients for different periods of time to allow copulation. Further, crude seeds of $V$. unguiculata were added in the closed pots and the insects were maintained for additional $24 \mathrm{~h}$ to permit oviposition. At the end of this period, the insects and latices were discarded and the number of eggs laid on the seeds was determined. In control experiments, distilled water was used instead of latices.

Statistical analyses: Each experiment was repeated at last twice with four replicates and independent controls in all cases. The results were expressed as mean \pm SEM using the statistical facilities of GraphPad Prism ${ }^{\circledR}$ software by analysis of variance (ANOVA) followed by Dunnett's Multiple Comparison Test at $p>0.001$ (Bioassays N. 1, 2 and 4), and Bonferroni's post Test (Bioassays N. 3 and 5).

\section{RESULTS}

Results of the bioassay N. 1 are summarized in Table 1. The laticifer fluids exhibited deterrent activity on oviposition of both insects assayed. Treatment of seeds with latex of $C$. procera, $E$. tirucalli and $H$. drasticus induced better deterrent effect reducing ovipositon of $C$. maculatus in many orders of magnitude while latex of $\mathrm{Cr}$. grandiflora and $P$. rubra were less effective but still active. 
The deterrent effect of these samples on oviposition of Z. subfasciatus followed the same trend. However, $\mathrm{Cr}$. grandiflora and $P$. rubra were as potent as the other latex fluids exhibiting distinct activity towards oviposition of the insects. Coating seeds with gelatin did not reduce oviposition of insects compared to crude seeds. However, in a few cases, ovipostion was slightly augmented. This observation was not considered as interference since the two control groups were not studied on a comparative basis. Coating seeds with gelatin before treating them with latex fluids did not interfere with the deterrent activity. However, it was interesting to observe that deterrent activity was augmented in seeds coated with gelatin and further treated with $P$. rubra compared with seeds coated only with $P$. rubra (Table 1).

In all cases, survival rate and larvae weight, recorded 17 days after the eggs had hatching were statistically similar among experimental groups and controls (data not shown). These results suggest that latex fluids do not alter ratio of eggs hatching neither larvae development. It is concluded that active compounds in latices inhibit only oviposition.
When serially diluted in water, $C$. procera diminished its deterrent activity on $C$. maculatus oviposition compared to that recorded in Table 1, but was still active. However dose dependence was not evident (Figure 1). On the other hand, deterrent activity on Z. subfasciatus oviposition was completely eliminated when the latex of $C$. procera was diluted. The same profile was observed when latex of $P$. rubra was tested against $Z$. subfasciatus. P. rubra lost the deterrent activity against $C$. maculatus only at the highest dilution assayed (Figure 1). These results suggest a dosedependent effect on Z. subfasciatus oviposition when tested with both latices. Bioassay N. 2 was performed to determine the possible involvement of laticifer proteins, rubber or small metabolites in the deterrent activity. The procedure to isolate the whole laticifer proteins has been published in several of our own works and checked by electrophoresis. For more information and details of the methodology see Freitas et al. $(2007,2010)$. The other two fractions are merely the complementary material of the fractionated latices obtained by precipitation or exclusion by dialysis.

Table 1. Deterrent activity of latex fluids against ovipositon of two bruchidae pests.

\begin{tabular}{|c|c|c|c|c|c|}
\hline \multirow{2}{*}{ Insects/treatments } & \multicolumn{5}{|c|}{ Latex fluids } \\
\hline & C. procera & Cr. grandiflora & P. rubra & E. tirucalli & H. drasticus \\
\hline \multicolumn{6}{|l|}{ C. maculatus } \\
\hline Crude seeds & $9.55 \pm 0.28$ & $8.95 \pm 0.46$ & $7.00 \pm 0.31$ & $6.67 \pm 0.55$ & $6.67 \pm 0.32$ \\
\hline Seeds+latex & $1.32 \pm 0.34^{\star *}$ & $6.52 \pm 0.44^{\star \star}$ & $5.00 \pm 0.24^{\star *}$ & $1.62 \pm 0.38^{* *}$ & $0.05 \pm 0.03^{\star *}$ \\
\hline Seeds+gelatin & $10.62 \pm 0.52$ & $9.15 \pm 0.38$ & $8.87 \pm 0.28$ & $5.25 \pm 0.41$ & $5.22 \pm 0.36$ \\
\hline Seeds + gelatin + latex & $0.9 \pm 0.18^{\star \star}$ & $5.07 \pm 0.36^{\star \star}$ & $2.27 \pm 0.31^{\star *}$ & $0.82 \pm 0.22^{\star *}$ & $0.05 \pm 0.04^{* *}$ \\
\hline \multicolumn{6}{|l|}{ Z. subfasciatus } \\
\hline Crude seeds & $6.87 \pm 0.38$ & $6.12 \pm 0.45$ & $8.20 \pm 0.48$ & $5.42 \pm 0.38$ & $6.60 \pm 0.64$ \\
\hline Seeds+latex & $1.05 \pm 0.35^{\star \star}$ & $0.70 \pm 0.27^{\star \star}$ & $0.52 \pm 0.27^{\star \star}$ & $3.92 \pm 0.45^{\star}$ & $3.22 \pm 0.60^{* *}$ \\
\hline Seeds + gelatin & $5.37 \pm 0.30$ & $7.37 \pm 0.51$ & $5.92 \pm 0.81$ & $5.17 \pm 0.33$ & $6.40 \pm 0.46$ \\
\hline Seeds + gelatin \pm latex & $0.27 \pm 0.25^{\star \star}$ & $0.61 \pm 0.25^{\star \star}$ & $0.07 \pm 0.07^{\star \star}$ & $3.75 \pm 0.31$ & $3.22 \pm 0.74^{* *}$ \\
\hline
\end{tabular}

Number of eggs laid by females on cowpea seeds coated with different preparations of crude latex fluids. Data are expressed as means \pm SEM $(n=40)$. $(p<0.05)$ or ${ }^{* *}(p<0.01)$ is significantly different comparing the treatment with the control (ANOVA-Dunnet's test). 

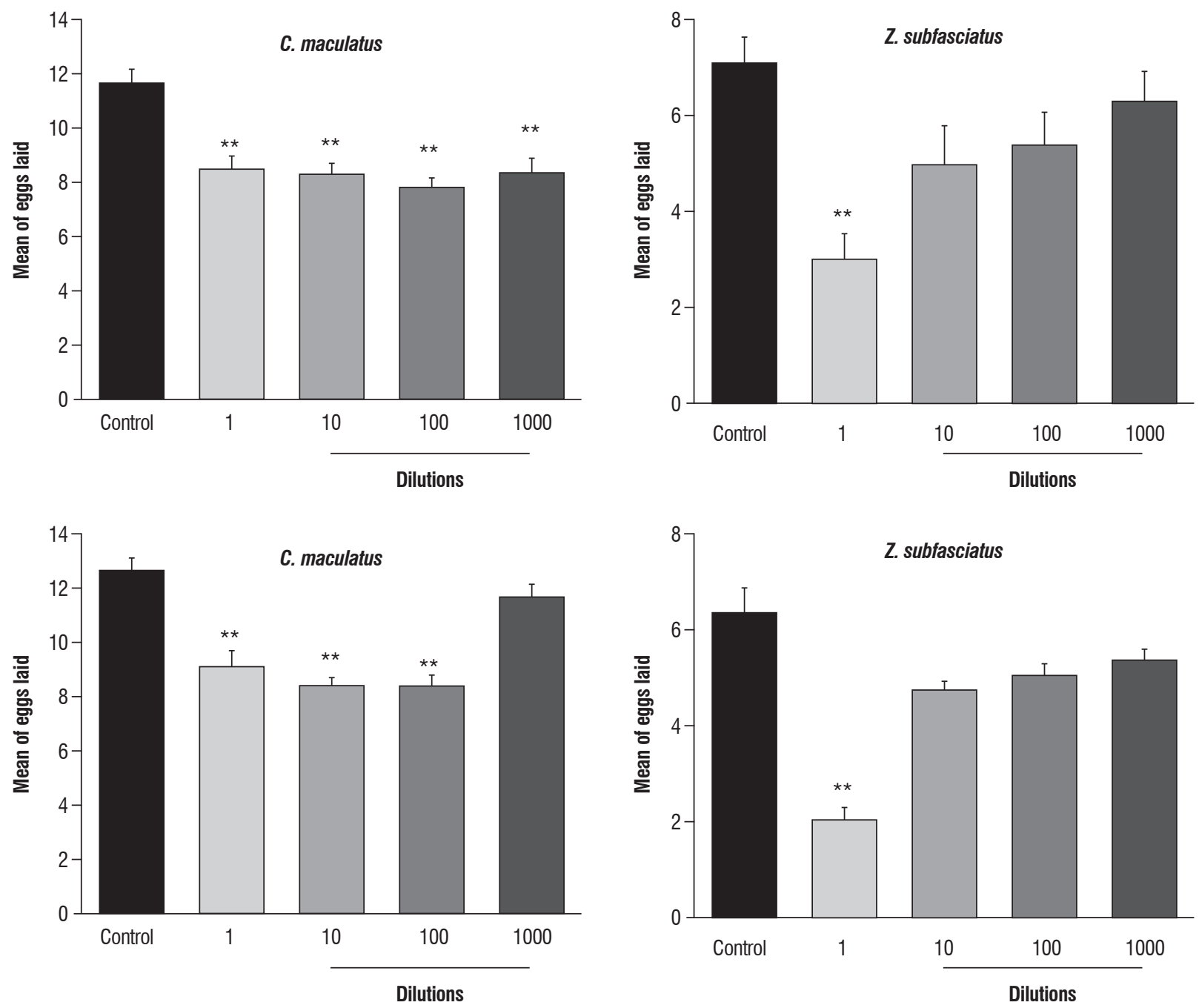

Figure 1. Performance of oviposition of $C$. maculatus and $Z$. subfasciatus on seeds of Vigna unguiculata treated with different dilutions of the laticifer fluids from C. procera (above) and $P$. rubra (below). Dilutions were prepared in water. ${ }^{* \star} p<0.01$ is significantly different when the treatments are compared with the control (ANOVA - Dunnet's Multiple Comparison Test).

The seeds were coated solely with latex proteins(1\%). Crude seeds and gelatin-coated seeds were used as controls. Performance of oviposition of both insects was uniform in all seeds. Even, survival rate and larvae weight were homogenous among the groups (data not shown). These results suggested that latex proteins are not involved in the deterrent activity. Surprising, rubber fraction and water of dialysis, the complementary fractions were both deprived of repellence. This observation gave rise to the hypothesis that the deterrent effect might be displayed by volatile secondary metabolites released from laticifer fluids. To explore this hypothesis, further analyses were performed with the whole latices of $C$. procera and $P$. rubra, both available in quantity enough. Bioassay N. 3 evaluated the deterrent effect along the time by treating the seeds with latex and storing them for different intervals of time prior to being exposed to insects. The deterrent effect was irregular. Both $C$. procera and $P$. rubra lattices inhibited ovipostion of Z. subfasciatus even a month after the seeds were coated (Figure2). This result supports the belief that non-volatile substances are involved in the deterrent activity. However, oviposition of $C$. maculatus was reduced only in seeds pretreated with $C$. procerafor $6 \mathrm{~h}$. The deterrent effect of $P$. rubra continued but was lower than observed with Z. subfasciatus (Figure 2). Even, when the latices of $C$. procera and $P$. rubra were maintained overnight under stirring to assist releasing 
of volatile substances (Bioassay N. 4), both materials still exhibited deterrent activity. The deterrence of $C$. procera latex on Z. subfasciatus oviposition was still observed after $36 \mathrm{~h}$ while deterrent activity was time-dependent on C. maculatus. P. rubra latex diminished oviposition of both insects assayed in a time-dependent manner (Figure 3). In
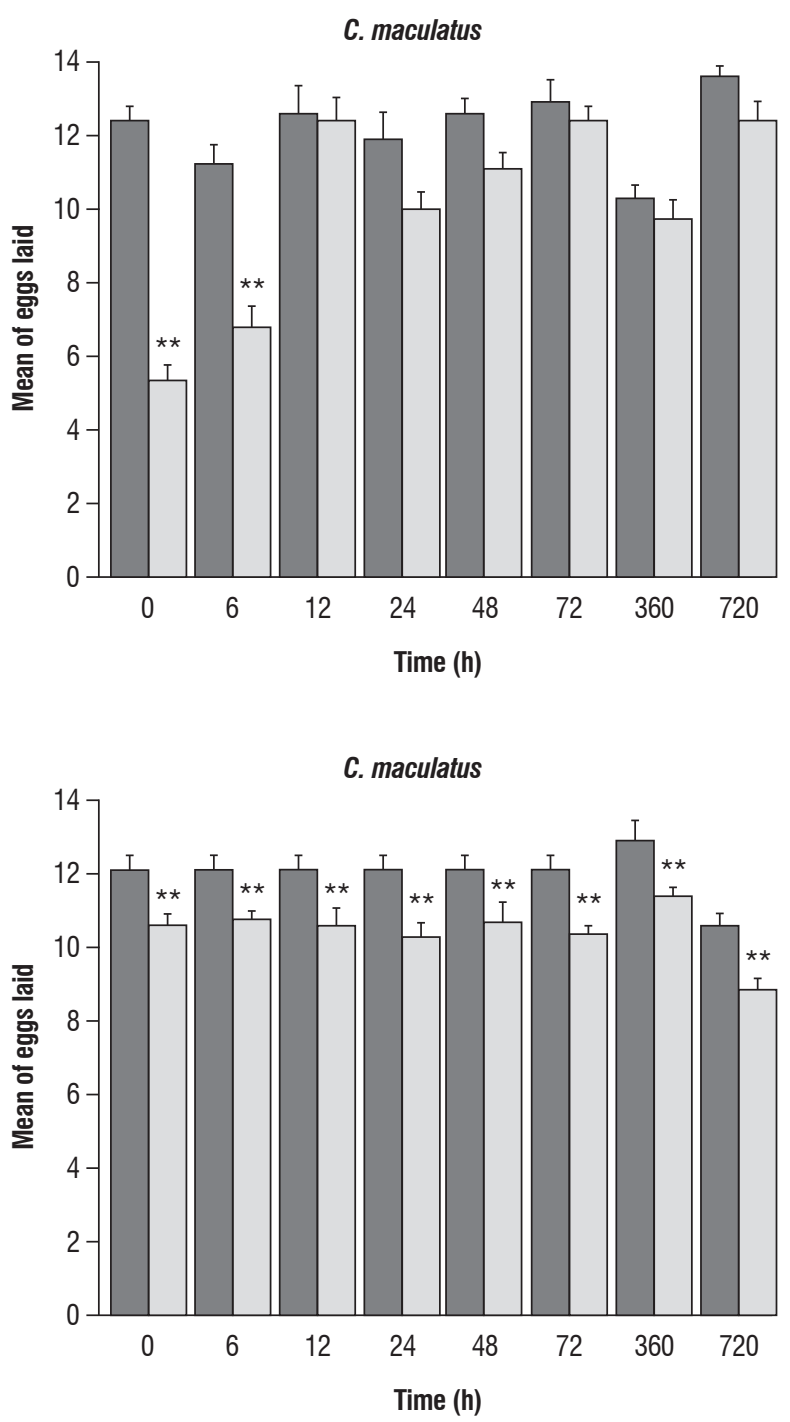

the light of these results, once more volatile substances do not seem to participate in the deterrent effect. It should be mentioned that after each period of stirring, the initial volume of the samples was recovered with distilled water, and thus the concentration of non-volatile substances in the lattices was considered almost constant.
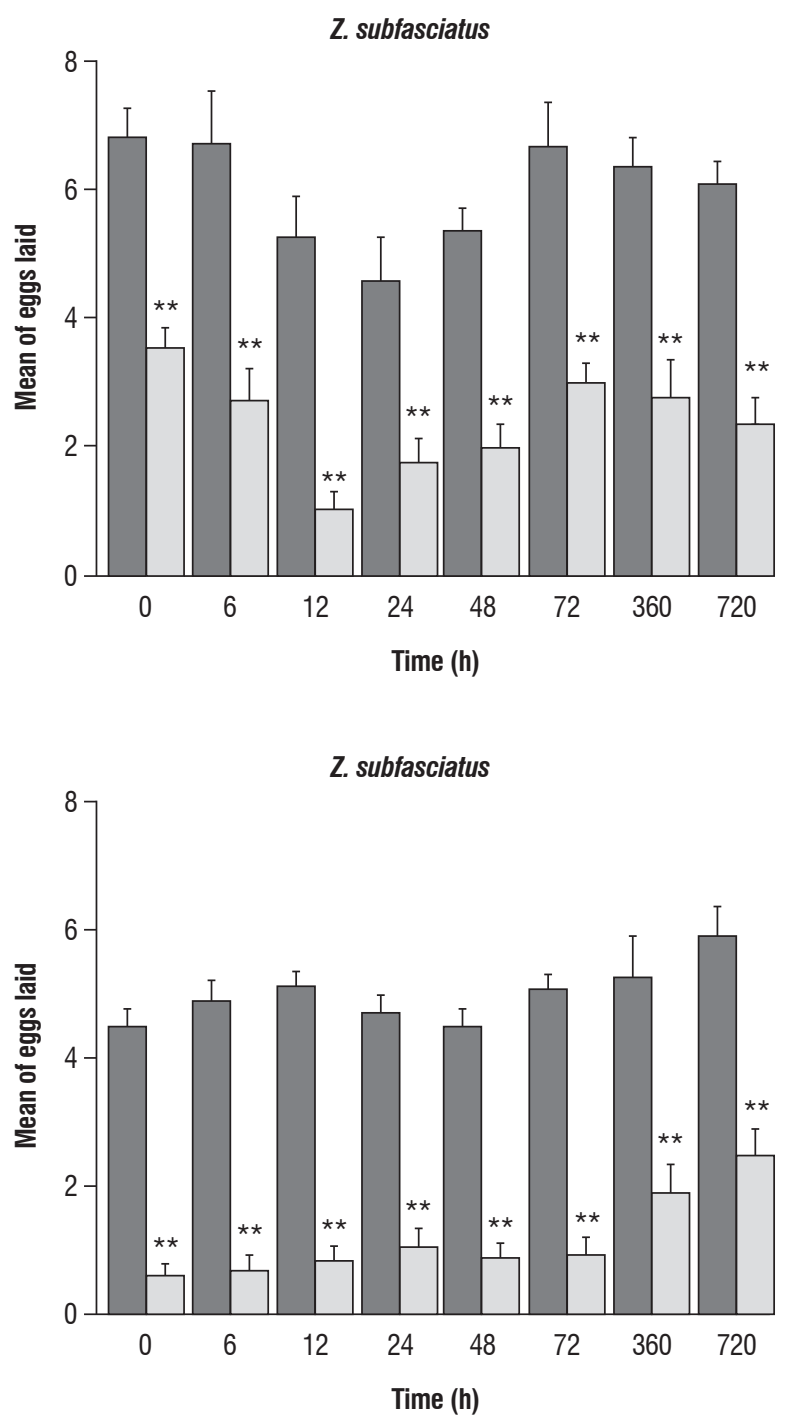

Figure 2. Performance of oviposition of $C$. maculatus and $Z$. subfasciatus along the time on seeds treated with the laticifer fluids from $C$. procera (above) and $P$. rubra (below). ${ }^{*} p<0.05$ and ${ }^{* *} p<0.01$ are significantly different when the treatment is compared with the control (ANOVA - Bonferroni's post Test). 

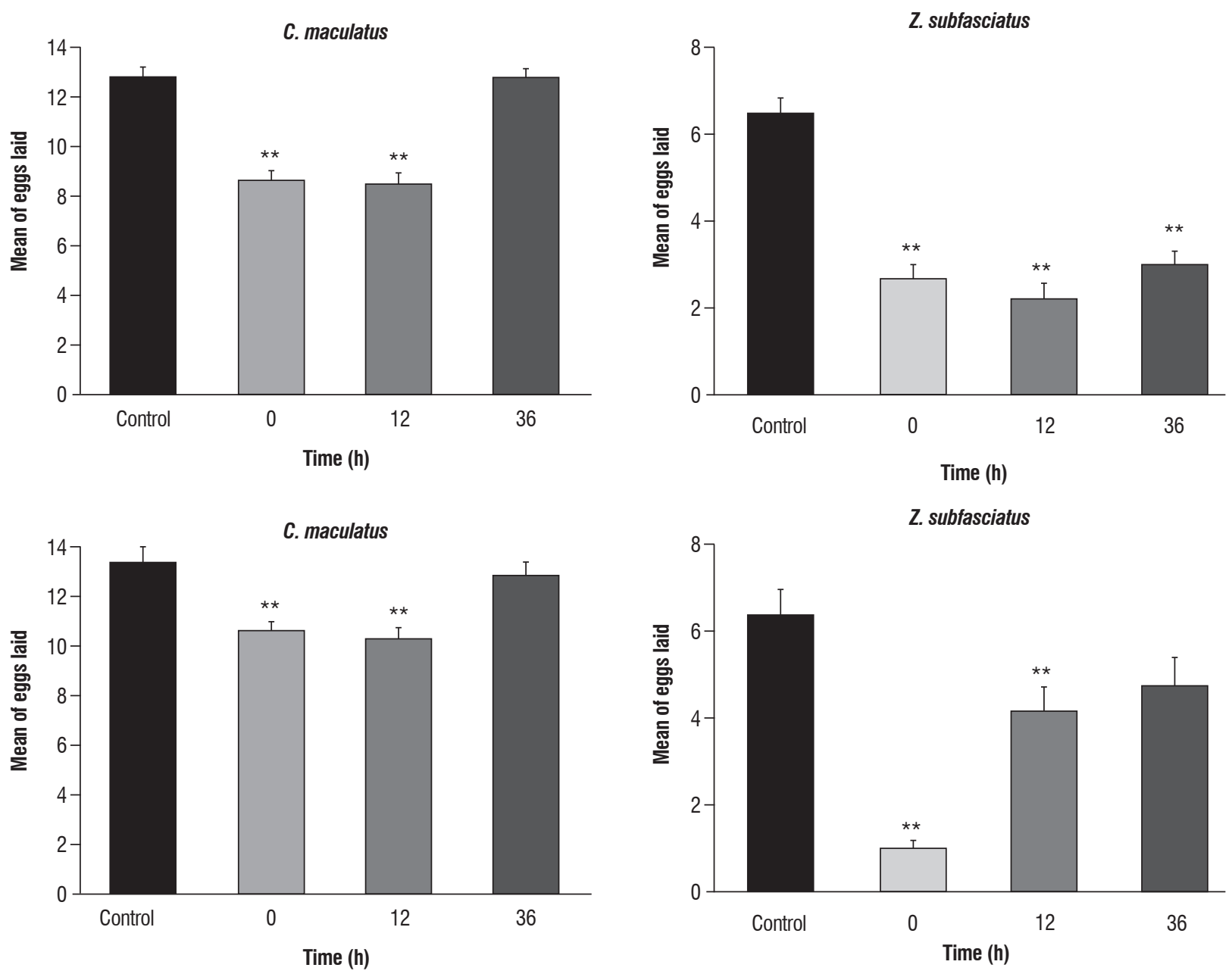

Figure 3. Performance of oviposition of $C$. maculatus and $Z$. subfaciatus on seeds of $V$. unguiculata treated with laticifer fluids from $C$. procera (above) and $P$. rubra (below) after different time of collecting latex. ${ }^{\star} p<0.05$ and ${ }^{* \star} p<0.01$ are significantly different when the treatment is compared with the control (ANOVA - Dunnet's Multiple Comparison Test).

Bioassay N. 5 was planned to evaluate whether crude latex was able to inhibit copulation or fertility and reduce oviposition mediated by a repellent-like effect. The results are summarized in Figure 4. The objective of this approach was to recreate a more reliable natural situation where insects were exposed to both latices. Oviposition of $C$. maculatus and Z. subfasciatus were not affected in the presence of $C$. procera latex, even after $24 \mathrm{~h}$ of exposition. C. maculatus insects exposed to the latex of $P$. rubra showed a reduced ratio of oviposition while this effect was not seen on $Z$. subfasciatus (Figure 4). 

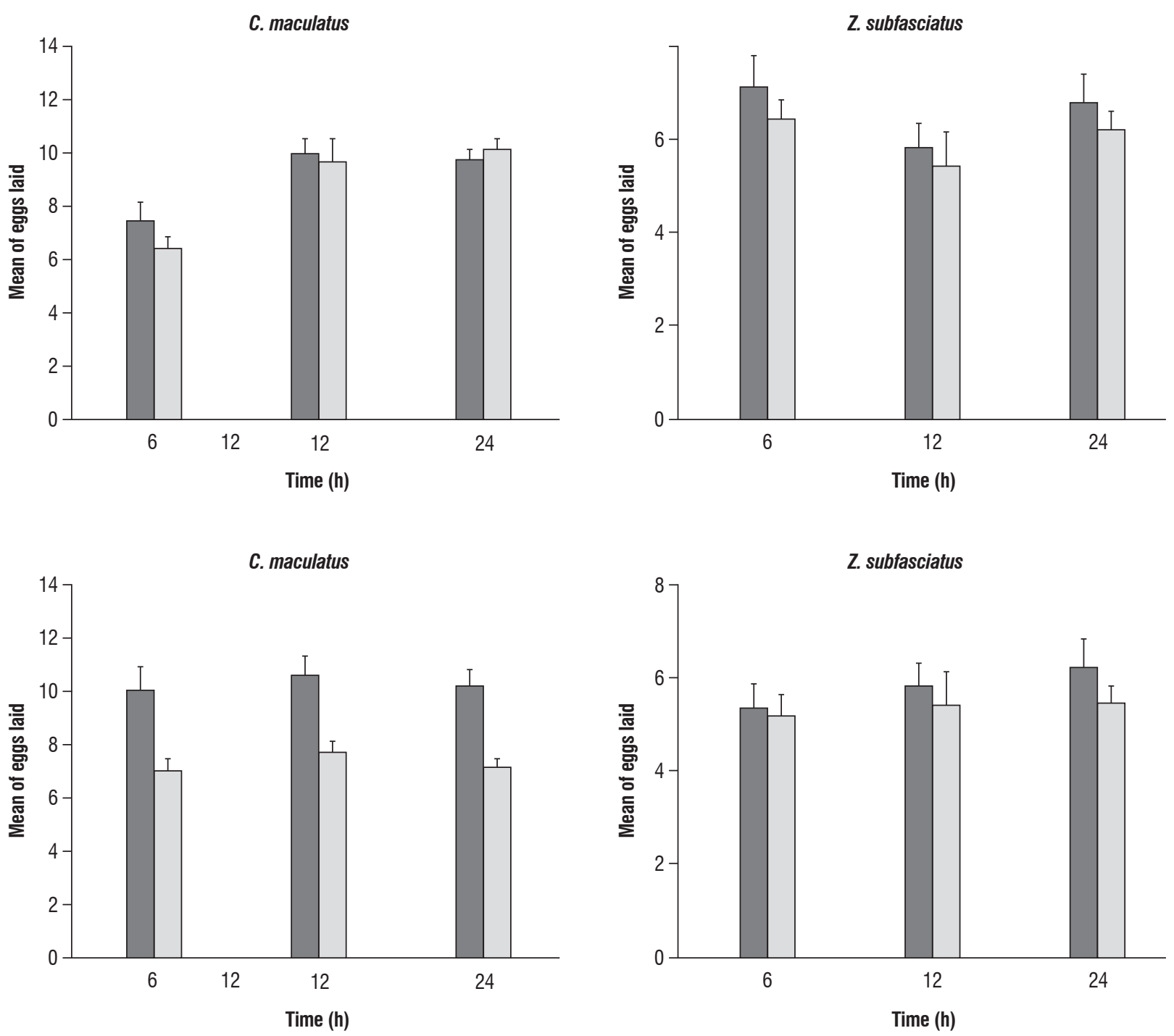

Figure 4. Performance of oviposition of $C$. maculatus and Z. subfasciatus on seeds of $V$. unguiculata after exposition to water $(\boldsymbol{\square})$ or laticifer fluids ( $\square$ ) from $C$. procera (above) and $P$. rubra (below). The insects were exposed to water or latices for different periods before the oviposition. ${ }^{* *} p<0.01$ is significantly different when the treatment is compared with the control (ANOVA - Bonferroni's Test).

\section{DISCUSSION}

Previously, it was reported deterrent activity of plant lectins on cowpea weevil oviposition (Sadeghi et al., 2006). It was noted that this activity was associated to the carbohydrate-binding activity of the assayed proteins. So far, attempts to detect lectin-like molecules in the latex fluids studied here have failed. The laticiferous proteins did not agglutinate red blood cells or interact with most common carbohydrate-based resins used for purification of lectins. The protein nature of these latex fractions has been described in the literature and in this study was checked by electrophoresis (Freitas et al., 2007, 2010). The lack of deterrent activity observed here in all the assays performed with laticifer proteins gives important evidence to exclude laticifer proteins as restraint molecules. However, the fact that the latex fluids retained their deterrent activity even after long periods of seed coating or after being stirred under reflux did not substantiate our hypothesis that volatile compounds are active molecules implicated in deterrent activity. Further investigation will be necessary to clarify this point. A limiting point in this study was the lost of deterrence when latices were fractionated in 
proteins, rubber and other small molecules. This observation highlights the complexity of the samples. Deterrence was only seen when the whole latices were tested. On the other hand, lack of deterrence in water of dialysis may be due to the dilution of this material. Despite this uncertainty,flavonoids obtained from $C$. procera were shown to control proliferation of $C$. chinensis reared on $V$. radiata seeds (Salunke et al., 2005). Toxic effects included reduction on oviposition, ovicidal effect and affecting the number and weight of adults. Recently, 2-tridecanone was shown to produce deleterious effects on $C$. maculatus when $V$. unguiculata seeds were pretreated with different doses of this monoterpene (Braga et al., 2007). Vapor of 2-tridecanone provoked a reduction in the number of eggs laid, in the percentage of eggs hatched and in the number of emerged adults in infested seeds. The fumigant insecticidal effect of 2-tridecanone was reported to be due to its ovicidal activity. Such an effect was completely discarded in the present study, since the hatching of eggs and larvae development were not affected by latices at all. Other putative latex metabolites candidates to exhibit repellence include many other alkaloids and phenolic glycosides which have been described in laticiferous fluids and have been recently revised (Hagel et al., 2008). It should be mentioned that deterrent activity may be a consequence of a repellent effect. In this respect, the latex of $C$. procera was already reported.

The defensive role of latex in plants has been reinforced by different studies. It is important to cite that laticiferous proteins from $C$. procera have been shown to be deleterious to some crop pests but not to other (Ramos et al., 2007, 2010). Furthermore we have recently demonstrated that both $C$. procera and $P$. rubra laticifer proteins are highly detrimental to both insects tested here when added in artificial diets (to appear elsewhere). These observations highlight the multi-defensive role of latex in plants. Further detailed identification of molecules involved in different defensive activities of laticiferous fluids will certainly contribute to the understanding of the biological significance of these saps in plants. The number and diversity of chemicals synthesized by laticifer cells and different plants are still poorly studied. A phytochemical profile of these fluids is not available at the present but this study represents a valuable tool to stimulate this approach.

In conclusion, this study suggests that laticifer fluids synthesize and store substances that, once released, some of their constituents can combine to act as repellents and impair insect approximation. This activity adds to other defensive strategies of laticifer plants already claimed to occur inthese fluids. Further studies with these latices and other insects would greatly contribute to a better understanding of the molecular basis of the repellent-like effect of laticifer fluids reported here.

Acknowledgements: This work was supported by CNPq, CAPES, FUNCAP and MCT/PADCT. M.V.R. is grantee of International Foundation for Science (IFS 3070-3). The authors are in debt with Mr. Brian Stephen Curry who critically reviewed the language of the manuscript.

\section{REFERENCES}

Albuquerque TM, Alencar NM, Figueiredo JG, Figueiredo IS, Teixeira CM, Bitencourt FS, Secco DD, Araújo ES, Ana Maria Leão CA, Ramos MV (2009) Vascular permeability, neutrophil migration and edematogenic effects induced by the latex of Cryptostegia grandiflora. Toxicon 53:15-23.

Al-MezaineHS, Al-RajhiAA, I-AssiriA, WagonerMD (2005) Calotropis procera (ushaar) keratitis. Am. J. Ophthalmol. 139:199-202.

AzarkanM, AmraniA, NijsM, VandermeersA, ZerhouniS, SmoldersN, LoozeY (1997) Carica papaya latex is a rich source of a class II chitinase. Phytochem 46:1319-1325.

BragaYF, Grangeiro TB, Freire EA, LopesHL, Bezerra JN, Andrade-NetoM, Lima MA (2007) Insecticidal activity of 2-tridecanone against the cowpea weevil Callosobruchus maculatus (Coleoptera:Bruchidae). An. Acad. Bras. Cienc. 79:35-39.

Farias LR, Costa FT, Souza LA, Pelegrini PB, Grossi-de-Sá MF, Neto SM, Bloch Jr.C, Laumann RA, Noronha EF, Franco OL (2007) Isolation of a novel Carica papaya $\alpha$-amylase inhibitor with deleterious activity toward Callosobruchus maculatus.Pestic. Biochem. Physiol. 87:255-260.

Freitas CDT, Oliveira JS, Miranda MRA, Macedo NMR, Sales MP, Villas-Boas LA, Ramos MV (2007) Enzymatic activities and protein profile of latex from Calotropis procera. Plant Physiol. Biochem. 45:781-789.

Freitas CDT, Souza DP, Araújo, ES, Cavalheiro MG, Oliveira LS, Ramos MV (2010) Anti-oxidative and proteolytic activities and protein profile of laticifer cells of Cryptostegia grandiflora, Plumeria rubra and Euphorbia tirucalli. Braz. J. Plant Physiol. 22(1): 11-22

Hagel JM, Yeung EC, Facchini PJ (2008) Got milk? The secret life of laticifers. Trends Plant Sci. 13:631-639.

Han KH, Shin DH, Yang J, Kim IJ, Oh SK, Chow KS (2000) Genes expressed in the latex of Hevea brasiliensis. Tree Physiol. 20:503-510.

Kalita D, Saikia CN (2004) Chemical constituents and energy content of some latex bearing plants. Bioresource Technol. 92:219-227.

Kekwick RG (2001) Latex and laticifers, Encyclopedia of Life Sciences. p. 1-6.

Konno K, Hirayamura C, Tateishi K, Tamura Y, Hattori M (2004) Papa in protects papaya trees from herbivorous insects: role of cysteine proteinases in latex. Plant J 37:370-378.

Papachristou TG, Nastis AS, Mathur R, Hutchings MR (2003)Effect of physical and chemical plant defenses on herbivory: implications for Mediterranean shrub land management. Basic Applied Ecol.4:395-403. 
Pickard WF (2008) Laticifers and secretory ducts: two other tube systems in plants. New Phytol. 177: 877-888.

Ramos MV, Freitas CDT, Stanisçuaski F, Macedo LLP, Sales MP, Souza DP, Carlini CR (2007) Performance of distinct crop pests reared on diets enriched with latex proteins from Calotropis procera: Role of laticifer proteins in plant defense. Plant Sci. 173:349-357.

Ramos MV, Pereira DA, Souza DP, Araújo ES, Freitas CDT, Cavalheiro MG, Matos MPV, CarvalhoAFU (2009) Potential of laticifer fluids for inhibiting Aedes aegypti larval development: evidence for the involvement of proteolytic activity. Mem. Inst. Oswaldo Cruz 104:805-812.

RamosMV, Grangeiro TB, Freire EA, Sales MP, Souza DP, Araújo ES, Freitas CDT (2010) The defensive role of latex in plants: detrimental effects on insects. Arthropod-Plant Interact 4:57-67.

Sadeghi A, Van Damme EJM, Peumans WJ, Smagghe G (2006) Deterrent effect of plant lectins on cowpea weevil Callosobruchus maculatus (F.) oviposition. Phytochem 67:2078-2084.
Salunke BK, Kotkar HM, Mendki PS, Upasani SM, Maheshwari VL (2005) Efficacy of flavanoids in controlling Callosobruchus chinensis (L.) (Coleoptera:Bruchidae), a post-harvest pest of grain legumes. Crop Protection 24:888-893

Selvaraj Y, Pal DK (1984) Changes in the chemical composition and enzyme activity of two sapodilla (Manilkarazapota) cultivars during development and ripening. J. Horticul. Sci. 59:275-281.

Singhi M, Joshi V, Sharma RC, Sharma K (2004) Oviposition behaviour of Aedes aegypti in different concentrations of latex of Calotropis procera: Studies on refractory behavior and its sustenance across gonotrophic cycles. Dengue Bulletin 28:184-188.

Turillazzi E, Greco P, Néri M, Pomara C, Riezzo I, Fineschi V (2008) Anaphylactic latex reaction during anesthesia: The silent culprit in a fatal case. Forensic Sci. Internat 179:5-8. 